\section{Student-led oral health education for the homeless community of East London}

\author{
R. M. Pritchett, ${ }^{* 1}$ C. E. Hine, ${ }^{1}$ M. A. Franks ${ }^{1}$ and L. Fisher-Brown ${ }^{1}$
}

IN BRIEF
- Discusses the contribution students can
make to community-based oral health
education.
Provides an insight into the experience
and learning of dental students working
with the homeless community of Tower
Hamlets, City and Hackney, London.
- Explores the benefits of student
participation in a busy dental service,
enabling in-depth discussion with
patients without infringing on chair-time.

\begin{abstract}
Within the BDS curriculum, dental public health and the importance of social responsibility is clearly emphasised though often in a didactic manner, without practical application. Preventative concepts are taught and relayed to individual patients being treated within a dental school. The impact of oral disease on general health within disadvantaged communities is a problem commonly addressed by healthcare professionals. Part of this responsibility should be shared with and experienced by the next generation of dental practitioners through health education outreach programmes within the undergraduate curriculum. Not only will this benefit recipients within disadvantaged populations such as the homeless, but it will also develop and encourage a philosophy of social responsibility throughout the future careers of undergraduate dental and hygiene/therapy students. To explore the feasibility of achieving this objective, we devised an oral health awareness programme to address the needs of 'hard to reach' homeless people within the communities served by the Community Dental Service of Tower Hamlets, City and Hackney, London.
\end{abstract}

\section{INTRODUCTION}

Dental students are a useful adjunct for community-based dental services. They can assist in the delivery of oral health information and are keen to gain experience across a wide range of clinical environments. Our project explored the utilisation of students within the Community Dental Service (CDS) provided for residents of Tower Hamlets and City and Hackney (Barts Health NHS Trust) in East London, to deliver oral health education to homeless patients attending for treatment.

Half of England's rough sleepers are located in London, which has seen an increase of $30 \%$ in the 5 years up to 2009/10. ${ }^{1}$ Furthermore, the average life expectancy of a homeless person is a mere 40.5 years, $^{2}$ usually as a result of poor health. The delivery of healthcare is often met with a combination of complicating factors, termed 'tri-morbidity', consisting of physical ill health, mental health issues and drug or alcohol misuse. ${ }^{2}$

Homeless people have significantly higher levels of untreated dental disease that has

\footnotetext{
${ }^{1}$ Fourth Year Dental Student, Barts and The London School of Medicine and Dentistry

*Correspondence to: Rosie M. Pritchett

Email:rmzp@hotmail.co.uk
}

\section{Refereed Paper}

Accepted 17 April 2014

DOI: $10.1038 /$ sj.bdj.2014.595

${ }^{\circ}$ British Dental Journal 2014; 214: 85-88 a direct impact on their quality of life. ${ }^{3}$ Through the provision of restorative dental treatment, both psychosocial and physical functioning can be improved - enabling the re-establishment of self-confidence. Oral health related quality of life (OHRQoL) can be measured using the Oral Health Impact Profile (OHIP-14)..$^{3-5}$ Daly et al. ${ }^{3}$ found the most common impacts reported in South East London were 'aching in the mouth' and 'discomfort when eating'. Furthermore, the mean number of OHRQoL impacts experienced by the homeless population was over three times that experienced by an equivalent housed adult population. ${ }^{3}$ A homeless population surveyed in North and West Belfast had similar complaints, with nearly half feeling ashamed or selfconscious of the appearance of their teeth. ${ }^{4}$ It is thought that supplementing treatment with oral health education could generate a substantial impact on the general health of these patients. ${ }^{5}$

In 2004 the British Dental Association published Dental care for homeless people, ${ }^{6}$ which aimed to outline the existing provision of dental care and address obstacles faced when accessing care. The policy paper ${ }^{5}$ identifies dental schools as an important resource in treating the dental needs of homeless people. It notes that:

'Dental schools operate community placements for their students within the CDS, which may involve treating patients who are homeless - but there appear to be no arrangements at any of the UK's dental schools for ensuring that students gain experience of working with homeless people.'

The paper concludes that:

'There would appear to be a strong case for including in the UK undergraduate dental curriculum some reference to work with socially excluded groups, including homeless people... but experience could be gained by means of assisting with the provision of care by other agencies (such as the CDS) ${ }^{\prime 5}$

Other overseas institutes in the USA and Sweden have already embraced this idea. By including health outreach systems in the curriculum, students gain awareness of the challenges faced by homeless people and provision of dental care. ${ }^{7,8}$ At the University of North Carolina, students spend 4 hours per month volunteering within communitybased dental services. ${ }^{9}$ This aims to support development in communication skills and social responsibility via reflective methods, shaping future career direction and ethical responsibilities. ${ }^{8}$ Clinically, students at the University of New Jersey who had spent their final years' clinical time within communitybased placements had more experience of restorative treatment and felt more clinically prepared than those who spent it within the dental school. ${ }^{10}$

In 2011, the Department of Health commissioned London Pathways to set out a Homeless health standard ${ }^{2}$ providing 


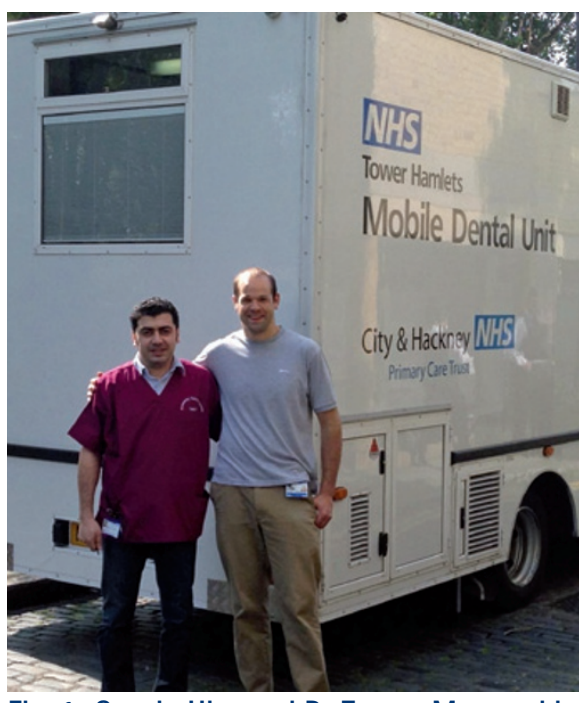

Fig. 1 Corwin Hine and Dr Zanyar Movasaghi outside the Mobile Dental Unit, which provides comprehensive NHS care for homeless people attending for scheduled or drop-in appointments

a national strategy for the healthcare of homeless people. This includes specific recommendations for the "education and involvement in undergraduate and postgraduate training of... dental students' in the 'promotion and encouragement of accessible provision of dental care.' ${ }^{2}$ The standard also identifies the beneficial use of 'regular outreach clinics in local hostels and drop-in centres... [so] all patients are offered drop-in clinics with presenting problems addressed first, but offered health screening to include... dental/oral problems.'

Barriers to receiving dental care can arise even with adequate service provision if there is an absence of uptake by the homeless people themselves. This can be due to psychosocial factors, such as lack of trust of health professionals and anxiety, or an inability to access services without an address or permanent dwelling. ${ }^{4}$ Homeless people in Birmingham, an area without a dedicated homeless service, did not know where to attend for emergency dental care. ${ }^{11}$ This was in contrast to other areas with a dedicated service, where they knew where to seek care and oral health knowledge was higher. ${ }^{11}$ Therefore, although psychosocial barriers exist, service provision is still important. The CDS of Tower Hamlets, City and Hackney successfully provide dental treatment to the homeless by adapting to their needs, for example, by increasing flexibility and accommodating missed appointments. ${ }^{12}$ A student presence may help where psychosocial barriers exist by providing a non-clinical setting to discuss oral health without the anxiety associated with being seated in the dental chair.

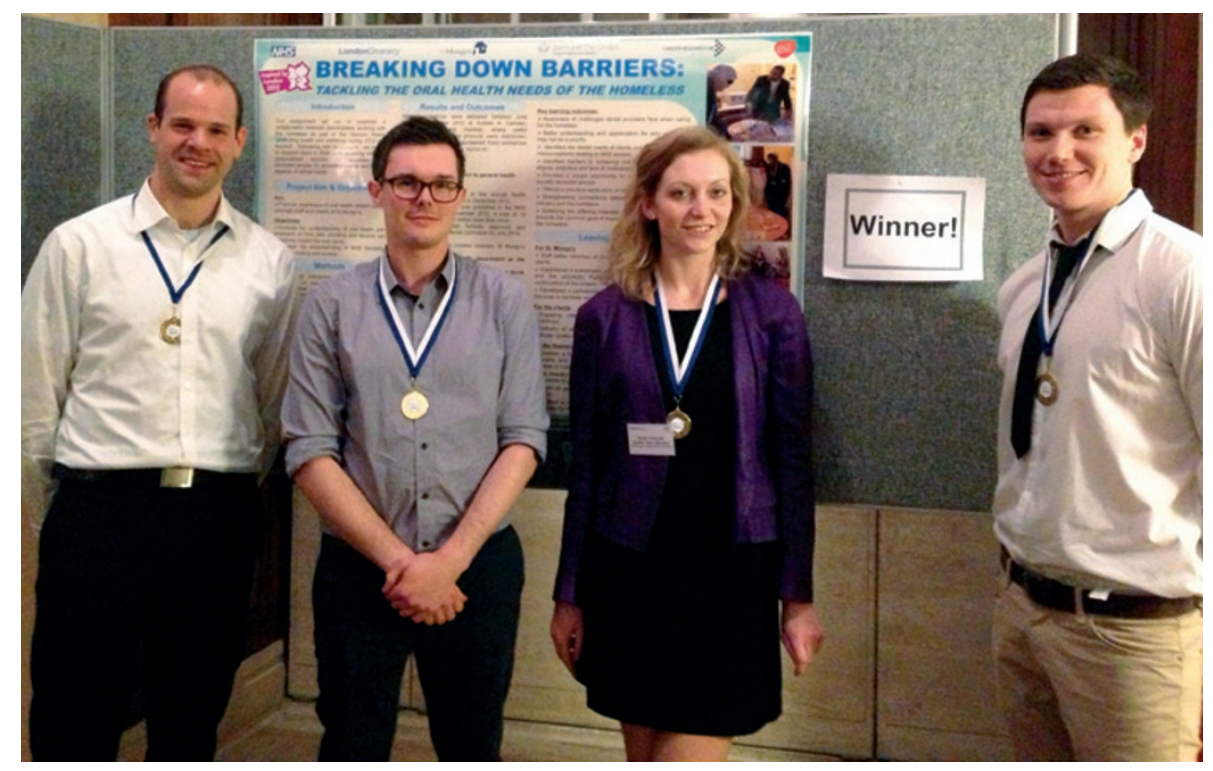

Fig. 2 The authors at the London Deanery Team Up award ceremony, part of a winning team led by dentist Avan Mohammed. The project piloted oral health education within St. Mungo's hostels. (From left to right: Corwin Hine, Mark Franks, Rosie Pritchett and Luke Fisher-Brown)

\section{AIMS AND OBJECTIVES}

Our aim was to assess the feasibility and implementation of student led oral health education within the CDS. With the intent to assist the CDS in the control of oral disease and at the same time encourage positive changes in the lives of the homeless people encountered over the study period.

If successful, this study will provide a platform for future student involvement in delivering oral health education to socially excluded and 'at risk' groups within the local community. Our key objectives were to enable students to gain first-hand experience of:

- A dental public health intervention

- Provision of dental care within the CDS

- Awareness of the problems encountered by homeless people seeking dental treatment

- Delivery of health promotion through oral health education.

\section{METHODOLOGY}

Our oral health awareness programme was developed by a group consisting of the authors working alongside Barts Health CDS. In East London, the CDS have developed an effective service, providing dental access to 2,000 homeless people a year, through a dedicated mobile dental service and dental clinics. ${ }^{12}$

As the CDS serve a large number of patients; there may be limited time for health education to be delivered effectively alongside treatment. Our plan was to develop a system whereby clinical care was delivered by qualified dentists, while students delivered oral health information tailored to each patient. This allows the
CDS to focus their time on treatment, while students deliver the majority of the oral health education and prevention advice. The finalised project was implemented through groups of two students attending either fixed or mobile dental sites visited by the CDS over a 6 day period (Fig. 1).

Previous health education experience was gained through workshops within St. Mungo's hostels as part of the London Deanery's Team Up initiative (Fig. 2), which focused upon four broad oral health topics; diet and oral health; periodontal disease; smoking, alcohol and oral cancer; and accessing NHS dental treatment. ${ }^{13}$ This formed the basis for the development of our intervention programme. Taking a risk factor approach by discussing smoking, alcohol and diet may help to improve overall quality of life. ${ }^{3}$ We produced information sheets to provide a framework for verbal prevention advice and to serve as hand-outs, which could be distributed to the homeless patients and looked at in their own time (Figs 3a and b). Efforts were made to design the information sheets in a user-friendly style, with straightforward explanations and diagrams. Complex scientific terminology was avoided.

It was decided that it would be best to tailor oral hygiene advice towards the individual patient, after observing the treatment performed by the dental practitioner. Verbal consent was obtained by the practitioner before introducing the student. At the end of each appointment the students and the patient would move to an adjacent room to discuss personalised oral health information based on the individual's problems highlighted during treatment. Toothbrushes, 

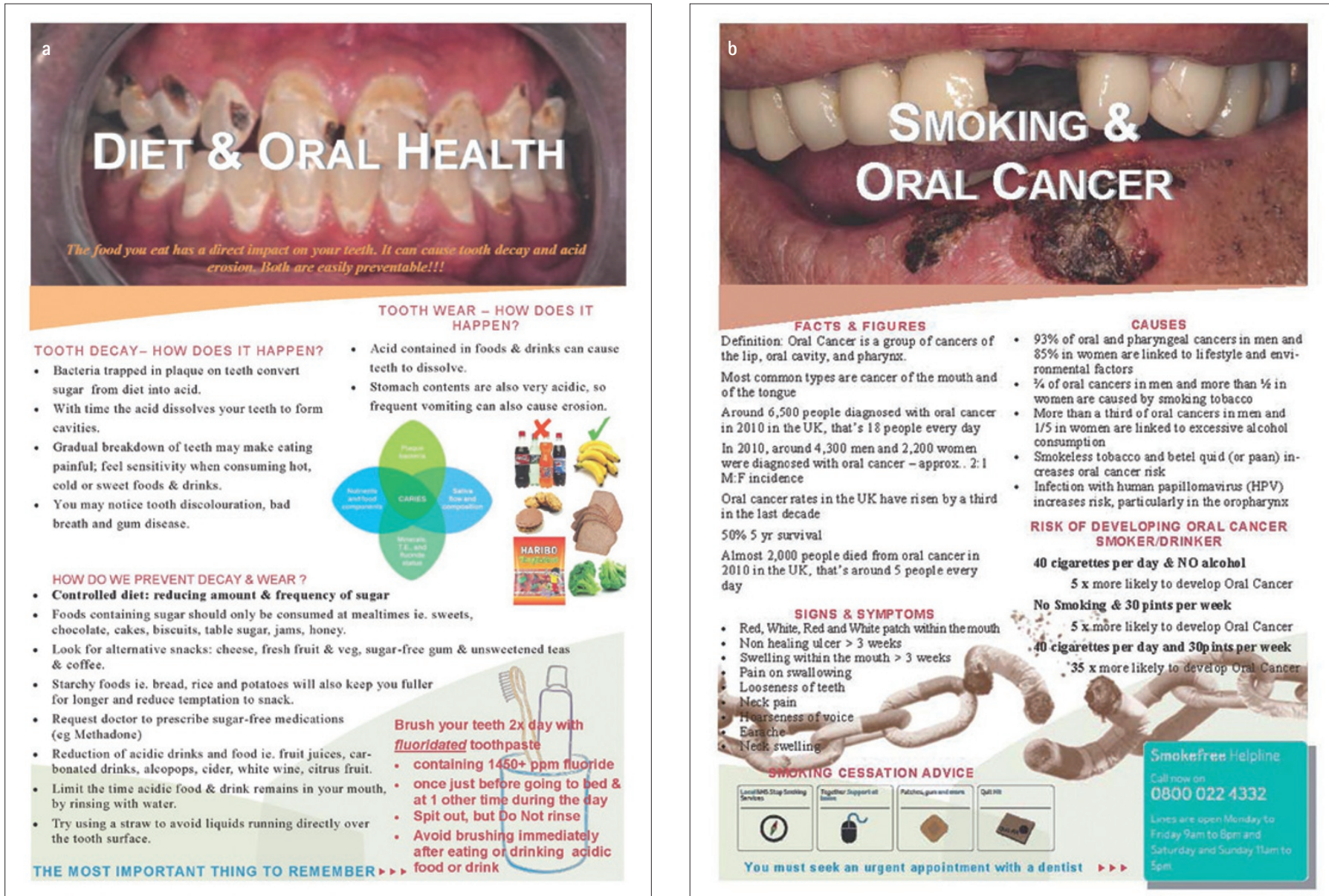

Fig. 3 Information sheets developed to engage and inform homeless patients about their oral health, 'Diet and oral health' (3a), 'Smoking and oral cancer' (3b)

toothpaste and mouthwash samples were given out in order to motivate favourable oral health behaviours and as an incentive to encourage participation. Short comments were obtained from the patients and the CDS practitioners in order to determine the practicality and effectiveness of the student service, and to assess the feasibility of such a project running alongside the CDS in the future.

\section{RESULTS AND FEEDBACK}

After each appointment, patients were given the opportunity to talk to a student about their oral health and write any comments relating to this experience. Out of the 36 appointments conducted by the CDS, all but one of the patients consented to student observation of their treatment, while all patients were comfortable talking about oral health with a student after their appointment.

Of the 36 patients who took part, 35 stated that they had found the session useful and 34 said that they would benefit from tailored oral health education on a regular basis.

We asked the patients if the oral health advice provided would affect their future behaviour; these were some of the comments received:
'I will start brushing my teeth in the morning'

'I will now try to brush my teeth twice a day'

'I am going to try to reduce my smoking'

We also asked patients whether they had learnt anything new from our oral health advice:

'I didn't realise that not keeping your mouth clean affects not just your teeth but also your gums'

'Talking about gum disease was really useful, it really made me understand the problems I am having'

'I have learnt things that may help me save the teeth I have remaining'

'Learnt some life changing instructions, I wish I had been told this earlier, I found the session really useful'

'I am concerned about the possibility of developing oral cancer, I have never heard about it before

Lastly we asked patients if they had any other comments that they felt they would like to give:

'The CDS are really great and generally have time to talk to me about my concerns. But other NHS dentists haven't in the past; I am really lucky to be seen here'

'It's been really useful talking to the students, I don't get enough time to talk to the dentist'

'I would like to have a nice smile again, so that I do not appear older than I am'

'Because of my oral health I have no confidence in myself and I have quit my social life'

We also asked one of the dentists to comment on his experience of having dental students available to provide oral health promotion to his patients:

'It's a win-win situation, we can utilise your skills, enthusiasm and time you give to this project, and maybe you could take some responsibilities in the long-term... if possible I think it would be very useful for us as well, for example we could leave the responsibility of oral hygiene advice to you... even before we go to the centre, if possible maybe you could go and do some oral health promotion and make the people who attend the hostels aware about the service and advertise that it will be visiting on a specific day.'

The dentist was also asked to comment on students supporting the CDS in the future with respect to delivering oral health promotion:

'Yes, you learn a lot of things that you cannot necessarily learn otherwise at this stage of your career, and you gain some 
experience and see things you cannot necessarily see elsewhere. It's also good for us because we can utilise your knowledge and enthusiasm so that this can be transferred to the patients.'

\section{CONCLUSIONS}

The feedback received from the homeless people encountered was positive and the majority found it useful talking to students about their oral health. Many attending the mobile clinic are often later successfully transferred to the fixed site clinic. ${ }^{10}$ It may be that student input is more beneficial within the mobile dental service where more of the homeless patients are likely to be at the start of their treatment. Provision of oral health advice by students may additionally improve patient confidence in accessing mainstream services. This is important as it is estimated that mobile service appointments are 2.4 times more expensive than within a fixed site. ${ }^{10}$

Over the study period, we encountered a diverse population of homeless people, which provided a unique opportunity to practice the delivery of fundamental topics central to the study of dentistry. Communication skills were enhanced by the need to secure and maintain interest, especially as it was optional for the homeless people to speak with us. Furthermore a certain level of understanding was gained in how to access and approach different people. The importance of delivery-style of oral health information was a useful learning outcome.

It has been previously stated that homeless people have a 'low priority given to oral hygiene' due to having more pressing 'survival needs., ${ }^{5}$ The impact of personal appearance varied from person to person, and in partially dentate or edentulous cases, basic needs such as the ability to eat took priority. Although poor oral hygiene was prevalent, many of the homeless people we spoke to were interested in how this could be improved and demonstrated the desire to keep multiple dental appointments as part of a longer treatment plan. Repeated student health promotion sessions would enable reinforcement of these ideas.
Within the homeless population there is a high prevalence of substance misuse, communicable diseases and chronic mental health problems. ${ }^{5}$ This may seem like an unsuitable environment for students; however, we always worked in a pair and didn't encounter any negative issues. Nevertheless, it is important to be mindful of the possible difficulties that could be encountered. The offer to talk with students about oral health was always optional and never forced.

Throughout the project we felt we were successful in engaging with the homeless people to promote interest and encourage positive health behaviours. On a wider scale, similar projects could be developed within other community services, allowing students to observe specialised dental treatment and management while contributing via the delivery of oral health education.

\section{EVALUATION}

In 2009-11, 99\% of the homeless people seen by the CDS of Tower Hamlets, City and Hackney required some form of treatment, $78 \%$ smoked and 86\% consumed alcohol daily. ${ }^{10}$ Treatment is important, but prevention of new and further disease progression is also paramount to oral health. Evidence from community-based health promotion methods, indicates that homeless people can be challenging to engage and that 'a tailored approach [must be adopted] to counteract the influence of insecure attachment styles and promote steady engagement.' ${ }^{3}$ Due to the short duration of the study period, uptake of our advice is unknown. We felt that there was interest and feedback was positive but the advice may have been disregarded quickly. There is variation in physical and mental health among homeless people that creates differing individual health priorities. ${ }^{4}$ Student impact may be greater on those in a reparatory phase who are actively seeking to improve their oral health. However, accessing as many homeless people as possible spreads awareness of the help available.

For this study, feedback was recorded. In the future, a stronger qualitative method to assess a correlation between patient anxiety
(OHIP-14) $)^{3}$ and the completion of longterm dental rehabilitation with and without student support would further elucidate the usefulness of student participation. With a continued student presence within our current project we certainly hope to record an improvement in oral health awareness among homeless people within our local community of East London.

The authors would like to thank Dr Zanyar Movasaghi of the Barts Health Community Dental Services for supporting the project and welcoming students into his working day. Special thanks to Professor Wagner Marcenes for his guidance, enthusiasm and suggestions during the formation of the project direction.

1. Crisis. A review of single homelessness in the UK 2000 to 2010. Crisis, 2010. Online review available at http://www.crisis.org.uk/publications-search. php?fullitem=294 (accessed May 2014).

2. Hewett N. Standards for commissioners and service providers. London: Pathway - Healthcare for Homeless People and College of Medicine, 2011. Online article available at http://www. Iondonpathway.org.uk/uploads/homeless_health_standards.pdf (accessed May 2014).

3. Daly B, Newton T, Batchelor $\mathrm{P}$, Jones K. Oral health care needs and oral health-related quality of life (OHIP-14) in homeless people. Community Dent Oral Epidemio/ 2010; 38: 136-144.

4. Collins J, Freeman R. Homeless in North and West Belfast: an oral health needs assessment. Br Dent J 2007; 202: E31.

5. Coles $E_{1}$ Chan $K_{1}$ Collins J et al. Decayed and missing teeth and oral-health-related factors: predicting depression in homeless people. J Psychosom Res 2011: 71: 108-112.

6. British Dental Association. Dental care for homeless people. Policy statement. London: BDA, 2004.

7. De Palma P, Frithiof L, Persson L, Klinge B, Halldin J, Beijer U. Oral health of homeless adults in Stockholm, Sweden. Acta Odontol Scand 2005; 63: 50-55.

8. Committee on Health Care for Homeless People. Homelessness, health and human needs. Boston: Institute of Medicine (USA), 1988.

9. Strauss R P, Stein M B, Edwards J, Nies K C. The impact of community-based dental education on students. J Dent Educ 2010; 74: S42-45.

10. De Castro J E, Bolger D, Feldman C A. Clinical competence of graduates of community-based and traditional curricula. J Dent Educ 2005; 69: 1324-1331.

11. Hill K B, Rimington D. Investigation of the oral health needs for homeless people in specialist units in London, Cardiff, Glasgow and Birmingham. Prim Health Care Res Dev 2011; 12: 135-144.

12. Simons D, Pearson N, Movasaghi Z. Developing dental services for homeless people in East London. Br Dent J 2012; 213: E11.

13. London Deanery. Team Up celebration award ceremony 2012. Online article available at http:// www.londondeanery.ac.uk/specialty-schools/publichealth/teamup/news/team-up-celebration-awardceremony (accessed May 2014) 